\title{
Call for papers: $N J L$ Special Issue on the Nordic Languages and Linguistic Typology
}

All modern linguistic science - all theoretical frameworks and approaches - at one point or another becomes linguistic typology. Sooner or later they ask the fundamental typological questions: What are the universal features of human language? How do we explain their universality? And how do we explain those features of human language which are NOT universal, but which vary from language to language? How do variation and universality relate to each other? The methodology of linguistic typology - to approach these questions by mapping and comparing language data globally - is not necessarily shared by all linguists, but the basic questions remain the same.

With this as our motto, we want to invite linguists from all fields and frameworks to discuss typological topics of linguistic variation and language universals in a special issue of $N J L$, to be published in November 2011. Although papers on typology in general are also welcome, we are especially interested in contributions dealing with the Nordic languages from a typological point of view. By 'Nordic languages', we mean not only the Scandinavian languages but also the other languages of the Nordic countries. All the Nordic languages occasionally share typological features through Sprachbund effects, and can thus be said to count as members of the same language area.

The Nordic languages are typologically interesting from several perspectives: Macro-typologically, a number of areal features worthy of notice are found here, e.g. V2-based sentential syntax (Scandinavian), expletive subjects (Finnish and Scandinavian), complex expressions of definiteness in noun phrases (Scandinavian), and the multiple number of close vowels (Scandinavian and Southern Sami).

Micro-typologically, the variation in dialects and varieties within the Nordic area is remarkable. Most of the features mentioned in the previous paragraph, and many others, vary significantly across the region. This makes the Nordic languages a gold mine for the dialectologist, and a dialectologist is a typologist, differing from the latter mainly by being dedicated to a geographically or genetically restricted set of languages.

In terms of contact linguistics and areal linguistics, the Nordic languages are also highly interesting typologically. In some respects, they constitute their own language area, characterized by a set of special features. In other respects, the Nordic languages are placed on or close to the dividing line between larger language areas, namely a 
Eurasian/Siberian area to the East, and a 'Standard European' area to the West and South, a position which is likely to have had effects on the local languages.

We therefore encourage authors to submit papers dealing with any such perspective on the meeting point between linguistic typology and the study of Nordic languages, although, as stated above, papers dealing with more general typological issues are also welcome. The deadline is January 31, 2011. Papers should be sent to one of the two guest editors:

$\begin{array}{ll}\text { Pål Kristian Eriksen } & \text { Camilla Wide } \\ \text { Scandinavian Studies and Comparative } & \text { Scandinavian Languages } \\ \quad \text { Literature } & \text { University of Turku } \\ \text { NTNU } & \text { FI-20014 University of Turku } \\ \text { NO-7491 Trondheim } & \text { Finland } \\ \text { Norway } & \text { camilla.wide@utu.fi } \\ \text { pal.k.eriksen@ntnu.no } & \end{array}$

